during the operation. Infants with left sided diaphragmatic hernia often have a mild degree of left ventricular hypoplasia. ${ }^{6}$ Their cardiac output is likely to be reduced, so it is not surprising that surgery is poorly tolerated. These infants could probably be helped by the use of dopamine started preoperatively, as used by Nair et al..$^{3}$

There was a coincidental increase in the use of abdominal wall grafts in infants treated by delayed surgery. It was our impression that their use benefited a few infants by facilitating ventilation. From autopsy evidence, however, we consider that only one infant not so treated would have benefited from a graft. It is therefore very unlikely that the improved survival was the result of the increased use of grafts.

We recommend that critically ill infants with congenital diaphragmatic hernia who present shortly after birth are stabilised before operation. If with this treatment the acidosis persists, with a $\mathrm{pH}<7 \cdot 20$, it is very unlikely that surgery will help.

We thank Miss M J Mayell for allowing us to study patients under her care, Dr S J Bodden, who was instrumental in devising the new protocol, and Mrs F Prew for typing the manuscript.

\section{References}

1 Levin DL. Morphologic analysis of the pulmonary vascular bed in congenital left-sided diaphragmatic hernia. $J$ Pediatr 1978;92:805-9.

2 Geggel RL, Murphy JD, Langleben D, et al. Congenital diaphragmatic hernia: arterial structural changes and persistent pulmonary hypertension after surgical repair. J Pediatr Surg 1985;107:457-63.

${ }^{3}$ Nair UR, Entress A, Walker DR. Management of neonatal $\overrightarrow{0}$ posterolateral diaphragmatic hernia. Thorax 1983;38:254-7.

${ }^{4}$ Manthei U, Vaucher Y, Crowe CP. Congenital diaphragmatic $\vec{\omega}$ hernia: immediate pre-operative and post-operative oxygen $O$ gradients identify patients requiring prolonged respiratory support. Surgery 1983;93:83-7.

5 Reynolds M, Luck SR, Lapper R. The 'critical' neonate with diaphragmatic hernia: a 21 -year perspective. J Pediatr Surg. 1984;19:364-9.

- Siebert JR, Haas JE, Beckwith JB. Left ventricular hypoplasia in congenital diaphragmatic hernia. J Pediatr Surg 1984;19: N $567-71$.

Correspondence to Dr P H T Cartlidge, Department of Neonatal 윽 Medicine and Surgery, City Hospital, Hucknall Road, Nottingham NG5 1PB. England.

Received 9 June 1986

\title{
Neonatal typhoid fever
}

\author{
K C CHIN, E J SIMMONDS, AND M J TARLOW
}

University of Birmingham, Department of Paediatrics and Child Health, East Birmingham Hospital

SUMmary Three infants of Pakistani immigrant mothers developed typhoid fever in the neonatal period. All three survived, but two became chronic excretors of Salmonella typhi. The risk of an outbreak of typhoid fever in a maternity unit or special care baby unit is emphasised.

Typhoid fever is rare in neonates. ${ }^{12}$ The public health problems it poses, however, are great. This report describes three neonates with typhoid fever born in two maternity hospitals in Birmingham over the past nine years.

\section{Case reports}

Case 1. After a normal birth and 24 hour discharge from Marston Green Hospital, Birmingham, a full term Pakistani girl presented at this hospital, very ill, shocked, and hypothermic at the age of 3 days. She had a 12 hour history of increasing lethargy and poor feeding.
After admission, she had a cardiorespiratory arrest and subsequently needed assisted ventilation for 48 hours because of attacks of apnoea. She also had episodes of clonic seizures and hypoglycaemia. A chest radiograph showed bilateral patchy consolidation. The blood culture grew Salmonella typhi phage type $E_{1}$ after incubation for three days. Results of lumbar puncture were normal. Repeated stool and urine cultures yielded negative results. Treatment with antibiotics was changed from ampicillin and gentamicin to trimethoprim when the results of the culture were known. Trimethoprim was given for two weeks, during which time she had neither fever nor diarrhoea. At 6 months the infant has microcephaly and neurodevelopmental delay. 요 Multiple stool cultures from the mother and her family have remained negative for $S$. typhi. No cross infection occurred while the baby was nursed in the intensive care unit where a strict hand washing policy was operated, although the baby was not isolated.

Case 2. After three days of intermittent fever 
Pakistani mother who had been in Pakistan three months earlier delivered a boy at 36 weeks' gestation at Marston Green Hospital. She had a postpartum fever $\left(40.8^{\circ} \mathrm{C}\right)$ and rigor and was treated with intravenous ampicillin. $S$. typhi of phage type $\mathrm{D}_{5}$ was isolated from her blood, stools, and urine. Her stool cultures remained positive for four months.

The infant was feverish immediately after birth and developed clinical and radiological signs of respiratory distress syndrome. He needed continuous positive pressure ventilation for 48 hours. On the fifth day the mother and baby were transferred to the infectious diseases unit at this hospital. Ampicillin was given parenterally for one week and orally for another two weeks. Apart from jaundice, intermittent fever, and frequent watery green stools between the fifth and eighth day, the natural history was uneventful. S. typhi phage type $D_{5}$ was isolated only from the infant's stools. No babies or staff of the special care baby unit were infected. The same organism was isolated, however, in stool specimens from the father and an aunt. At 7 months the infant was still excreting the bacteria. Furthermore, two mothers who had babies at around the same time in the maternity hospital were believed to have acquired $S$. typhi from the index case. A total of six children from these two families had $S$. typhi phage type $\mathrm{D}_{5}$ isolated from their stools. Two of these children were admitted to hospital with clinical infection.

Case 3. At 48 hours of age a Pakistani boy of 36 weeks' gestation who was born in Dudley Road Hospital, Birmingham, developed a temperature of $37.5^{\circ} \mathrm{C}$ and had several blood stained mucousy stools. The father had been in Pakistan a month earlier. A stool culture grew $S$. typhi phage type $E_{1}$. Blood and urine cultures yielded negative results. The mother was later found to be an asymptomatic excretor of $S$. typhi of the same phage type. The infant was isolated. Intravenous ampicillin was given for seven days followed by oral trimethoprim for another week. The infant was well apart from transient fever $\left(37.5^{\circ} \mathrm{C}\right)$ and some loose stools. At 4 weeks of age, however, he was still excreting $S$. typhi. His brother was also found to be an asymptomatic excretor. Stool cultures were not obtained from staff or patients. No cross infection was known to have occurred.

\section{Discussion}

Neonatal typhoid fever is usually acquired at birth. Vertical transmission of the infection is suggested in two of our infants by the concordant $S$. typhi phage type in mother and baby. The third infant (case 1) is also likely to have acquired the infection from the mother, despite the lack of a positive maternal stool culture. ${ }^{3}$

The clinical diagnosis may be more difficult to make than in adults. The classical 'rose spots' are not evident, especially in dark skinned infants. ${ }^{4}$ The incubation period is shorter and is usually only about 48 hours, although it may be up to seven days. ${ }^{2}$ Of eight neonates with enteric fever described by Duggan and Beyer, all had diarrhoea, but only one was febrile, while the others were afebrile or hypothermic. ${ }^{1}$ The clinical features in our infants are in keeping with these descriptions.

There is no ideal drug for the treatment of neonatal typhoid fever. Experience is limited to chloramphenicol and ampicillin. ${ }^{2}$ The risk of aplastic anaemia and the emergence of chloramphenicolresistant $S$. typhi have led, however, to the search for alternative antibiotics. In children and adults co-trimoxazole or trimethoprim ${ }^{5}$ when given parenterally are of proven efficacy. Our infant with septicaemia responded to trimethoprim given intravenously. Infants with mild $S$. typhi enteritis do not require treatment. The duration of diarrhoea or carrier state is not shortened by treatment with oral antibiotics. ${ }^{6}$ Two of our infants remained asymptomatic excretors despite treatment with oral antibiotics.

Our report highlights the health hazards that undetected asymptomatic $S$. typhi excretor mothers can bring to any maternity and baby unit. Only in case 2 was the possible spread of infection pursued vigorously. All the nursing and medical staff and patients in the labour, postnatal, and special care baby unit had stool cultures performed. The organism was isolated in two other mothers, who were discharged, and their families. It was fortuitous that a larger outbreak did not occur. As screening for excretion of $S$. typhi in pregnant mothers is not feasible we suggest that great care is taken when looking after infants with fever and diarrhoea, especially if their mothers are from developing countries.

We thank Dr E E Hill and Dr J G Bissenden for allowing us to include their patients in this report and $\mathrm{Dr} \mathrm{C} J$ Ellis for advice on management.

\footnotetext{
Keferences

1 Duggan MB, Beyer L. Enteric fever in young Yoruba children. Arch Dis Child 1975;50:67-71.

2 Marcy SM, Guerrant RL. Microorganisms responsible for neonatal diarrhoea. In: Remington JS, Klein JO, eds. Diseases of the fetus and newborn infant. London: W B Saunders, 1983; 948-65.

${ }^{3}$ Christie AB. Typhoid and paratyphoid fevers. In: Infectious diseases. Epidemiology and clinical practice. 3rd ed. Edinburgh: Churchill Livingstone, 1980:47-101.
} 
${ }^{4}$ Scragg J, Rubidge C, Wallace HL. Typhoid fever in African and Indian children in Durban. Arch Dis Child 1969:44:18-28.

${ }^{5}$ McKendrick MW, Geddes AM, Farrell ID. Trimethoprim in enteric fever. In: Penti P, Grass GG, eds. Current chemotherapy and immunotherapy. Proceedings of the 12th International Congress of Chemotherapy. (Florence 1981.) Vol. 2. Washington DC: American Society for Microbiology, 1982:957-8

${ }^{6}$ Nelson JD, Kusmiesz H, Jackson LH. Treatment of salmonella gastroenteritis with ampicillin, amoxicillin or placebo. Pediatrics 1980;65:1125-30.

Correspondence to $\mathrm{Dr} \mathrm{K}$ C Chin, University of Birmingham, Department of Paediatrics and Child Health, East Birmingham Hospital, Bordesley Green East, Birmingham B9 5ST, England.

Received 21 July 1986

\title{
Fluoride treatment in corticosteroid induced osteoporosis
}

\author{
F REJOU, R DUMAS, C BELON, P J MEUNIER, AND C EDOUARD
}

Clinique des Maladies des Enfants et d'Hygiène du Premier Age, Hôpital Saint-Charles, Montpellier Cedex, and Unité Inserm 234, Faculté Alexis Carrel, Lyon, France

SUMmaRY Severe osteoporosis with multiple vertebral fractures occurred in two girls receiving prolonged high dose corticosteroids for relapsing dermatomyositis. Sodium fluoride, supplemented with calcium and vitamin $\mathrm{D}$, helped control secondary osteoporosis in one case and should be considered as part of the curative treatment of corticoid induced osteoporosis.

Sodium fluoride is now used in idiopathic osteoporosis of aging adults, ${ }^{12}$ as it should be able to increase bone mass. Prolonged high doses of treatment with corticosteroids may produce severe osteoporosis in children. The histomorphometric and histodynamic method ${ }^{3}$ represents a quantitative approach to the evaluation of bone disease under treatment with fluoride.

\section{Case reports}

Case 1. A 10 year old, prepubertal girl was treated for dermatomyositis. From August 1980 to December 1982 she received the following treatment and dosages: prednisone $0.6-2 \mathrm{mg} / \mathrm{kg} /$ day, with calcifediol $100 \mu \mathrm{g} /$ day up to November 1981 and then alfacalcidol 0.5-1 $\mu \mathrm{g} /$ day up to December 1982, and also hydrochlorothiazide $75 \mathrm{mg} /$ day. No height gain was observed from January 1981 to December 1982. At this time her height was $128 \mathrm{~cm}$ and dermatomyositis was stable, but treatment with corticosteroids induced a severe osteoporosis and multiple vertebral fractures (D6, D7, D10, D12, and L5).

From December 1982 to April 1984 she received prednisone $0 \cdot 6-1 \cdot 1 \mathrm{mg} / \mathrm{kg} / \mathrm{day}$ on alternate days with alfacalcidol $(0.5 \mu \mathrm{g} /$ day $)$, calcium carbonate $(1.5$ $\mathrm{g} /$ day), and hydrochlorothiazide. Sodium fluoride was given at a dose of $1 \mathrm{mg} / \mathrm{kg} / \mathrm{day}$ for 16 months.
The height gain during this treatment was $10 \mathrm{~cm}$ and the girl remained impubertal. No other vertebral fractures occurred, and bone $x$ ray profile has improved.

Case 2. This 7 year old girl presented with dermatomyosistis in March 1981. She received an average dose of prednisone $1.4 \mathrm{mg} / \mathrm{kg} / \mathrm{day}$ with alfacalcidol $0.25-0.75 \mu \mathrm{g} /$ day and hydrochlor othiazide $75 \mathrm{mg} /$ day without calcium supplementa tion because of hypercalciuria. In October 1982 hex. height was $123 \mathrm{~cm}$ and the presence of multiple vertebral fractures (eight vertebras) revealed $\vec{a}$ severe osteoporosis associated with renal lithiasis. From June 1983 to May 1985 the dermatomyositis relapsed and treatment included prednisone $1.1 \mathrm{mg} / \mathrm{kg} /$ day in conjunction with sodium fluoride $1 \mathrm{mg} / \mathrm{kg} /$ day, alfacalcidol $0.5 \mu \mathrm{g} / \mathrm{day}$, and hydrochlorothiazide $75 \mathrm{mg} /$ day. During this time, the $x$ ray profile of the spine improved and no other vertebral fractures occurred. At the end of the study the girl remained prepubertal and ner height was $135 \mathrm{~cm}$.

In both cases, after tetracycline double labelling, a bone biopsy specimen was taken before and after treatment with fluoride. The histomorphometric and histodynamic variables were compared (Table).

\section{Discussion}

In both children the natural history and bone radiology during extended treatment with corticosteroids for dermatomyositis seemed typical of corticosteroid induced osteoporosis. We could not study bone photon absorptiometry, but bone biopsy specimens were contributive: appreciable decrease of trabecular bone volume with decrease of the calcification rates and increased trabecular resorption 